\title{
First record of the chimaera Neoharriota carri (Bullis and Carpenter 1966) in the Caribbean of Guatemala
}

\author{
Francisco Polanco-Vásquez ${ }^{1}$, Ana Hacohen-Domené ${ }^{*}$, Thalya Méndez ${ }^{1}$, Alerick Pacay ${ }^{1}$ and Rachel T. Graham²
}

\begin{abstract}
Background: A new record of Neoharriota carri is here reported for the Caribbean of Guatemala.

Results: Two chimaeras, a male and female Neoharriota carri, were caught with a single panel trammel net off the coast of El Quetzalito, Guatemala in February 2015 and January 2016 respectively. Details concerning the identification and measurement of these species are presented.

Conclusions: These records represent the first records in Guatemalan waters and the northernmost records in the western Atlantic for the distribution of $\mathrm{N}$. carri.
\end{abstract}

Keywords: Rhincomeridae, First record, Range extension, Caribbean

\section{Background}

The family Rhincomeridae, belongs to the subclass Holocephali, order Chimaeriformes, commonly known as the longnose chimaera. Longnose chimaeras are small to medium chondrichthyans with a broad head and elongated spear-like snout. Currently, Rhincomeridae is represented by three genera: Harriota Goode and Bean 1895, Neoharriotta Bigelow and Schroeder 1950, and Rhinochimaera Garman 1901. Species of Neoharriota are distinguished from Harriota by the possession of a prominent anal fin. Neoharriota species are represented by: N. pinnata, Schnakenbeck 1931, which appear to be restricted to the eastern Atlantic, off the western coast of Africa, N. pumila, Didier and Stehmann 1996, presently known only from the northwestern Indian Ocean and $N$. carri with known occurrence in the upper and mid continental slopes in the Southern Caribbean (219-458 m depth range) (Bullis and Carpenter 1966).

Globally, Chimaeroids are captured incidentally in commercial, recreational and artisanal fisheries (Barnett et al. 2012). Despite captures, few data exist regarding their population status; the International Union for

\footnotetext{
*Correspondence: ahacohen@fundacionmundoazul.com

${ }^{1}$ Fundación Mundo Azul, Blvd. Rafael Landivar 10-05 Paseo Cayala Zona 16,

Edificio D1 Oficina 212, Guatemala City, Guatemala

Full list of author information is available at the end of the article
}

Conservation of Nature lists 16 out of 35 chimaera species as data deficient (IUCN 2011). During February 2015 and January 2016, while conducting landings verification of elasmobranchs in Quetzalito, a fishing village on Guatemala's Caribbean coast, two specimens of the chimaera Neoharriota carri were collected, with the 2016 specimen was being preserved for further examination.

\section{Methods}

On $14^{\text {th }}$ February 2015 and $30^{\text {th }}$ January 2016, two chimaera specimens were captured by artisanal fishermen of El Quetzalito, Izabal (Fig. 1). According to the fisherman, both specimens were captured approx. $16 \mathrm{Km}$ from El Quetzalito, Izabal, Guatemala $\left(15^{\circ} 52.374 \mathrm{~N}, 88^{\circ}\right.$ $18.712 \mathrm{~W})$, approximately $240 \mathrm{~m}$ depth, with a $1000 \mathrm{~m}$ bottom trammel net of $3.5 \mathrm{in}$. mesh size and one panel. Images of the 2015 specimen as well as total length (TL) and sex were recorded for the captured chimaera in 2015. The specimen captured in 2016 was kept on ice and later preserved in formaldehyde $(10 \%)$ for 3 weeks before finally being transferred to ethyl alcohol (70\%) and donated to the Laboratory of Biological Science and Oceanography, Centro de Estudios del Mar y Acuicultura (CEMA) of the Universidad San Carlos de Guatemala (USAC). The specimen is part of the 


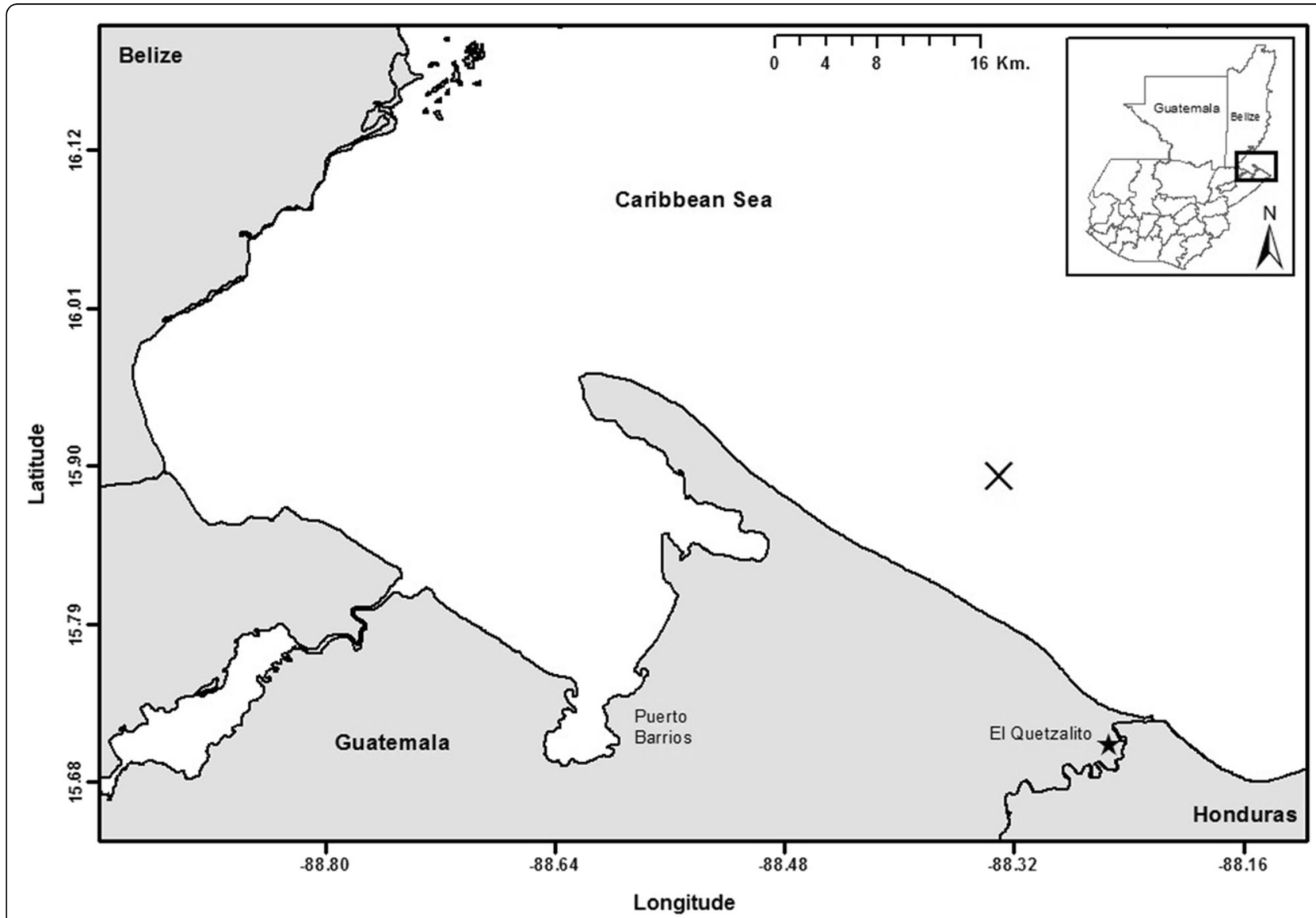

Fig. 1 Study area with locations of capture in relation to the fishing village of El Quetzalito

collection registered to the Consejo Nacional de Áreas Protegidas (CONAP) under the reference number 162.

The 2016 specimen was measured using a ruler and measuring tape. A total of 46 measurements were taken (Table 1) as proposed by Compagno et al. (1990) and Bullis and Carpenter (1966). Specimen examination and species confirmation were based on Didier (2002) and Bullis and Carpenter (1966).

\section{Results}

Systematic account

Family: Rhinochimaeridae Garman, 1901

Genus: Neoharriotta Bigelow and Schroeder, 1950

Neoharriotta carri Bullis and Carpenter 1966

Common name: Dwarf sicklefin chimaera; Quimera pálida con hocico largo (Spanish), tiburón elefante (local name).

\section{Material examined}

2015 specimen, male 730 mm TL (Fig. 2). 2016 specimen, female, $880 \mathrm{~mm}$ TL, $349 \mathrm{~mm}$ body length (BDL)

(Table 1, Fig. 3).

\section{Description}

2016 specimen: Medium to large. Snout elongated and pointed. Caudal fin axis weakly raised, prominent anal fin present and is separated from ventral caudal lobe. Caudal filament broken off. Pectoral and pelvic fins are triangular in shape, darker in color than the body. First dorsal fin is preceded by a spine. Second dorsal fin base terminates immediately above and slightly anterior to anal fin origin.

For the 2015 specimens, photographs were taken by the fishermen for evidence (Fig. 2), but no specimen was kept for preservation or further identification. Based on the fisherman's report and on images taken with known reference lengths, this specimen was male with a $730 \mathrm{~mm}$ TL, presumed mature due to clasper formation and size (Dagit 2006).

A year later, in January 2016, the same fisherman collected a new specimen: a female chimaera, $880 \mathrm{~mm}$ TL (Fig. 3). This specimen was identified as Neoharriota carri and according to size at sexual maturity (Dagit 2006), this organism was also presumed to be sexually mature. 
Table 1 Measurements of preserved Neoharriota carri landed in El Quetzalito, Guatemala on January 2016

\begin{tabular}{|c|c|}
\hline Measurements (mm) & Female $(n=1)$ \\
\hline Total length (TL- caudal filament broken off) & 880 \\
\hline $\begin{array}{l}\text { Precaudal length }(\mathrm{PCL}) \text {, snout tip to posterior end } \\
\text { of anal fin base }\end{array}$ & 646 \\
\hline Body length (BDL), gill opening to upper caudal origin & 349 \\
\hline Prenarial length (PRN) & 142 \\
\hline Preorbital length (POB) & 179 \\
\hline Head length (HDL) & 249 \\
\hline Head height (HDH) & 81 \\
\hline Head width (HDW) & 53 \\
\hline Prepectoral length (PP1) & 277 \\
\hline Prepelvic length (PP2) & 420 \\
\hline Trunk height (TRH) & 85 \\
\hline Trunk weight (TRW) & 36 \\
\hline Caudal peduncle height (CPH) & 21 \\
\hline Caudal peduncle width (CPW) & 11 \\
\hline Pectoral length (P1L) & 86 \\
\hline Pectoral anterior margin (P1A) & 175 \\
\hline Pectoral base (P1B) & 38 \\
\hline Pre first dorsal length (PD1) & 264 \\
\hline Pre second dorsal length (PD2) & 382 \\
\hline Snout vent length, snout tip to front of anus (SVL) & 442 \\
\hline Snout greatest width (SWF) & 19 \\
\hline Snout basal width (SWB) & 41 \\
\hline Snout basal height (SHB) & 34 \\
\hline Mouth length (MOL) & 16 \\
\hline Mouth width (MOW) & 30 \\
\hline Upper labial furrow length (ULA) & 27 \\
\hline Lower labial furrow length (LLA) & 4 \\
\hline Upper labial furrow height (ULH) & 10 \\
\hline Nostril width (NOW) & 7 \\
\hline Internarial space (INW) & 34 \\
\hline Outer internarial space (IOW) & 37 \\
\hline Anterior nasal flap length (ANF) & 11 \\
\hline Eye length (EYL) & 31 \\
\hline Eye height (EYH) & 22 \\
\hline Eye mouth space (EMO) & 12 \\
\hline Interorbital space (INO) & 21 \\
\hline Trunk length (TRL) & 194 \\
\hline First dorsal insertion to second dorsal origin (IDS) & 28 \\
\hline Dorsal caudal space (DCS) & 61 \\
\hline First dorsal anterior margin (D1A) & 105 \\
\hline Length dorsal spine (DSA) & 94 \\
\hline Second dorsal fin length (D2L) & 164 \\
\hline Second dorsal fin base (D2B) & 162 \\
\hline
\end{tabular}

Table 1 Measurements of preserved Neoharriota carri landed in El Quetzalito, Guatemala on January 2016 (Continued)

Second dorsal fin height (D2H) 31

First dorsal height (D1H) 101

First dorsal base (D1B)

Second dorsal length (D2L) 4

Total caudal length (CTL) 248

Dorsal caudal margin (CDM) 198

Caudal filament length (CFI-broken off) 51

Maximum caudal height (CHI) 44

Ventral caudal margin (CVM) 215

Pelvic caudal space (PCA) 180

Caudal lower ray length (CLR) 35

Caudal upper ray length (CUR) 6

Gill opening (gill split) (GS1) 34

Prenarial length (PRN) 162

Preoral length (POR) 165

Pectoral pelvic space (PPS) 149

Intergill width (IG1) 40

Anal fin length (AL) $\quad 27$

Anal fin base (AB) 11

\section{Discussion}

$N$. carri was first described by Bullis and Carpenter (1966), who described a female holotype of $428 \mathrm{~mm}$ TL, collected in Panama. In Colombia, Acero (1998) reported the occurrence of two individuals, 1 female $640 \mathrm{~mm}$ TL and 1 male $820 \mathrm{~mm}$ TL. N. carri has also been reported in Venezuela (Dagit 2006). Benavides et al. (2014), recorded $N$. carri while using bottom

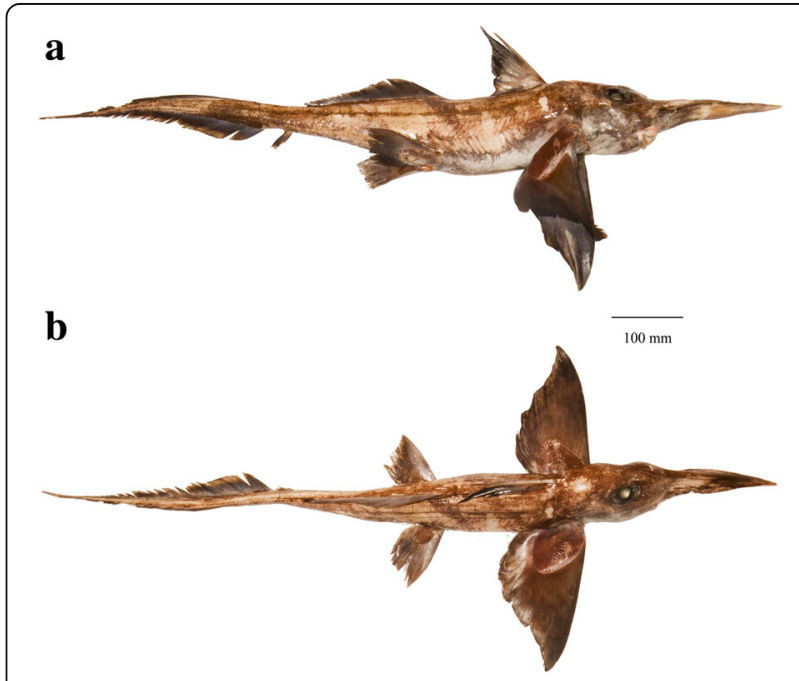

Fig. 2 Chimaera specimen collected near El Quetzalito, in Guatemala (February 2015), male, $730 \mathrm{~mm}$ TL (a. lateral view, b. dorsal view) 


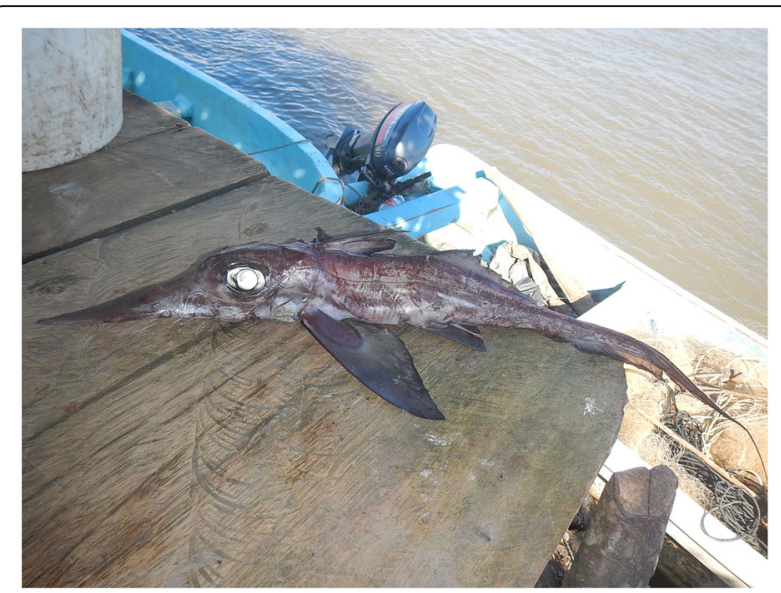

Fig. 3 Neoharriota carri (Bullis and Carpenter 1966) collected near El Quetzalito, in Guatemala (January 2016), female, 860 mm TL, 349 mm BDL, (A- lateral view; B-dorsal view)

trawling nets in Costa Rica. During these surveys in Costa Rica, the authors collected a large number of specimens, 31 males (285-545 mm TL) and 31 females (285-545 mm TL), all presumed sexually immature per Dagit (2006). According to Acero (1998), the maximum size reported for this species is $820 \mathrm{~mm}$ TL. The 2016 specimen described here is therefore the largest specimen on record ( $880 \mathrm{~mm} \mathrm{TL})$.

To date fishers report catching at least 10 additional $N$. carri specimens near the actual coordinates at which the specimens were found. There is no reported seasonal variance in the captures of this species. Captured $N$. carri are generally released at sea, but if landed, are neither corned and/or consumed as is customary with other chondrichthyan species.

\section{Conclusion}

The importance of the present records resides in the fact that they represent the first record of $N$. carri for Guatemala and a significant range extension and northernmost report in the Western Atlantic. No targeted fisheries exist for this species, and captures represent bycatch from traditional small-scale finfish and elasmobranch fisheries.

\section{Abbreviations}

BDL: Body length; Km: Kilometer; m: Meter; TL: Total length

\section{Acknowledgements}

FUNMZ would like to thank the community of El Quetzalito for their constant support to the research program in the area. Also, we would like to thank Josué Ayala for reporting the collection of the specimen.

\section{Availability of data and materials}

The specimen is available at the Laboratory of Biological Science and Oceanography, Centro de Estudios del Mar y Acuicultura (CEMA) of the Universidad San Carlos de Guatemala (USAC). The specimen is part of the collection registered to the Consejo Nacional de Áreas Protegidas (CONAP) under the reference number 162. Additionally, photographs and dataset supporting the conclusions of this article are included.

\section{Authors' contributions}

$\mathrm{FP}, \mathrm{AH}$ participated in the identification of the species, supporting literatures and contributed to draft the manuscript. TM, AP, RTG participated in the identification of the species and contributed to draft the manuscript. All authors read and approved the final manuscript.

\section{Competing interests}

The authors declare that they have no competing interests.

\section{Consent for publication}

Not applicable.

\section{Ethics approval and consent to participate}

Not applicable.

\section{Author details}

${ }^{1}$ Fundación Mundo Azul, Blvd. Rafael Landivar 10-05 Paseo Cayala Zona 16, Edificio D1 Oficina 212, Guatemala City, Guatemala. ${ }^{2}$ MarAlliance, 32 Coconut Drive, Po Box 283, San Pedro, Belize.

Received: 15 June 2016 Accepted: 6 December 2016

Published online: 03 January 2017

\section{References}

Acero A. Registros nuevos de peces cartilaginosos para el Caribe Colombiano. Actu biol. 1998;17(63):36-39.

Barnett LAK, Ebert DA, Cailliet GM. Evidence of stability in a chondrichthyan population: case study of the spotted ratfish Hydrolagus colliei (Chondrichthyes: Chimaeridae). J Fish Biol. 2012;80:1765-88.

Benavides R, Brenes CL, Márquez A. Análisis de la población de condrictios (Vertebrata: Chondrichthyes) de aguas demersales y profundas del Caribe centroamericano, a partir de faenas de prospección pesquera con redes de arrastre. Rev Cienc Mar Cost. 2014;6:9-27.

Bullis Jr HR, Carpenter JS. Neoharriotta carri: A New Species of Rhinochimaeridae from the Southern Caribbean Sea. Copeia. 1966;3:443-50.

Compagno LJV, Stehmann M, Ebert DA. Rhinochimaera africana, a new longnose chimaera from southern Africa, with comments on the systematics and distribution of the genus Rhinochimaera Garman, 1901 (Chondrichthyes, Chimaeriformes, Rhinochimaeridae). S Afr J Marine Sci. 1990;9:201-22.

Dagit DD. Neoharriotta carri. In: The IUCN Red list of threatened species. 2006. e. T60141A12312391. http://dx.doi.org/10.2305/IUCN.UK.2006.RLTS. T60141A12312391.en. Accessed date 30 March 2016.

Didier DA. Chimaeras. In: Carpenter KE, editor. FAO species identification guide for fishery purposes. The living marine resources of the western central Atlantic, Vol. 1: Introduction, molluscs, crustaceans, hagfishes, sharks, batoid fishes, and chimaeras. 2002. p. 591-6.

IUCN. IUCN Red List of Threatened Species: Version 2011.1http://www.iucnredlist. org. Accessed date 30 March 2016. 